\title{
Microlearning for improved student outcomes in higher education: A scoping review
}

\author{
Adrian B. R. Shatte ${ }^{1^{*}}$ \\ Samantha J. Teague ${ }^{2}$ \\ ${ }^{1}$ Federation University, School of Engineering, Information Technology and Physical \\ Sciences, Berwick, Australia \\ ${ }^{2}$ Deakin University, Centre for Social and Early Emotional Development, School of \\ Psychology, Faculty of Health, Geelong, Australia
}

* Corresponding author: Dr Adrian Shatte, School of Engineering, Information Technology \& Physical Sciences, Federation University, 100 Clyde Rd, Berwick VIC 3806.

$\mathrm{Ph}$ (+613) 5122 6801. Email: a.shatte@ federation.edu.au 


\section{Abstract}

This paper aims to synthesise the literature on technology-based microlearning in higher education. Six education, information technology, and interdisciplinary research databases were searched using key terms relating to technology-based microlearning in higher education. Articles were assessed by two reviewers, and data were extracted on the article's microlearning features, supporting technologies, educational discipline, and outcomes for teaching and learning. Articles were then synthesised via narrative review. Forty papers focusing on the application of technology-based microlearning to higher education were identified. Three keys themes emerged, including: (i) methods for microlearning design and delivery; (ii) the impact of microlearning on objective student outcomes (e.g. academic performance and participation); and (iii) the impact of microlearning on subjective student outcomes (e.g. motivation to learn and user experience of using microlearning technologies). Overall, the application of microlearning to higher education has demonstrated a range of benefits for both objective and subjective student outcomes. With the majority of studies reporting on small-scale studies conducted across various disciplines, it is evident that there is significant room for further research on the application of technology-based microlearning to further understand the nuances of its application in higher education. Combined, the results of the current study collate the existing evidence on the benefits and limitations of microlearning in higher education, and can thus assist educational practitioners in incorporating microlearning content into their own teaching materials.

Keywords: Distance education and online learning, Mobile learning, Post-secondary education, Teaching/learning strategies 


\section{Introduction}

Advances in technology, including the use of social media, smartphones, and big data, have paved the way for significant changes in the educational landscape (Daniel, 2019; Gikas \& Grant, 2013). With these new technologies, education practitioners have experienced a shift in teaching pedagogy, with paradigms such as blended learning (Boelens et al., 2017), flipped classrooms (O’Flaherty \& Phillips, 2015), flexible and online learning (Appana, 2008), Massive Open Online Courses (MOOCs) (Bozkurt et al., 2017), and gamification (Subhash \& Cudney, 2018) becoming increasingly common. These new teaching paradigms available through technological advances have also changed the way that students learn, with contemporary students having greater access to learning materials and technologies than previous generations. While these new technologies and paradigms promise a range of benefits to both the teacher and student alike, their implementation and effective use are not without challenges (Kirkwood \& Price, 2014). In order to ensure that teaching and learning technologies are utilised in an effective way, alternative methods for teaching must be explored that take into account both the benefits and limitations of these technologies.

One emerging paradigm made possible through technology is microlearning, defined loosely as the delivery of learning sessions or activities of shorter duration than traditional teaching delivery (Hug, 2010). Microlearning principles overlap with technology-assisted learning (e.g. mobile devices) and ubiquitous learning (e.g. any-time, anywhere learning) through the use of short videos, context-awareness, mobile and distributed delivery (Semingson et al., 2015). The design of microlearning is based on psychological research suggesting that learning is improved by grouping content into smaller, meaningful groups for better recall, known as "chunking” (Fountain \& Doyle, 2012). Further, cognitive load theory states that learners have limitations on short-term memory, so breaking learning content into a short, concise format may also assist with memory encoding (Kirschner, 2002). While there 
is evidence that students studying in e-learning environments may prefer content designed according to the principles of microlearning (Javorcik \& Polasek, 2018), it remains unclear whether microlearning content delivered using technology is effective at improving student learning outcomes, engagement, and overall learning experience.

A literature review on microlearning for higher education is pertinent and timely, given the ongoing trends towards alternative, technology-assisted teaching and learning methods for students in higher education. While there are a wealth of studies published that explore microlearning in the higher education context, the definition of microlearning is broad so it can include various content formats, delivery styles, and supporting technologies (Hug, 2010). Further, the focus of the literature is spread across several different educational disciplines and contexts, while also using vastly different technologies to study the impacts of microlearning. This makes it challenging for educators to determine whether microlearning is effective in different disciplines, and how to effectively utilise various learning technologies with microlearning to ensure positive educational outcomes. Previous reviews include De Gagne et al. (2019), Lin et al. (2019), and Shail (2019); however, these reviews are limited in their focus to specific disciplines, methods, or non-systematic identification of relevant literature. Therefore, we aim to broadly review the application of technology-based microlearning to higher education, providing a synthesis of the current state of the field and how it impacts on educational outcomes and the teaching and learning experience.

\subsection{Objective}

This scoping review aimed to provide a concise snapshot of the research to date investigating the application of microlearning to higher education. To the best of our knowledge, no review has been completed that has comprehensively mapped the application of microlearning to higher education to explore impacts on both objective (e.g. academic performance and participation) and subjective (e.g. motivation and student satisfaction) 
measures of student outcomes. Such a review would equip educators in higher education with insights into how microlearning can be used effectively in the classroom, by focusing on the benefits of applying different types of microlearning content and technologies across various disciplines. It would also highlight the benefits and challenges of using technology-based microlearning in higher education, as well as identify any gaps or limitations in the field and identify potential opportunities for future research. The remainder of this paper is structured as follows. First, we outline the search strategies used to find relevant literature. Next, a synthesis of the literature is described in terms of technology and microlearning strategy, impacts on academic performance of students, and impacts on the teaching and learning experience of students in higher education. Finally, the paper provides a summary of the research to date, including potential limitations and opportunities for future research.

\section{Materials and Methods}

A scoping review methodology was followed to achieve the goal of mapping the literature on technology-assisted microlearning in higher education and its impact on educational outcomes and the teaching and learning experience. According to Arksey and O'Malley (2005), the purpose of a scoping review is to rapidly map the key concepts underpinning a research area and identify the main sources of evidence available, particularly in areas that have not previously been reviewed comprehensively.

\subsection{Search Strategy and Study Selection}

This scoping review utilised a systematic method, adhering to the Preferred Reporting Items for Systematic Reviews and Meta-Analyses (PRISMA) guidelines (Moher et al., 2010). As the primary goal of this scoping review was to explore technology-assisted microlearning in higher education generally, the search was conducted in education, Information Technology (IT), and broader multidisciplinary databases, including EBSCO databases 
(Academic Search Complete, ERIC, and Education Source), IEEE Xplore, the ACM Digital Library, and Scopus. The search query focused on MESH key terms surrounding the use of mobile and web technologies, education, and microlearning (see Supplementary Table 1 for full list of search terms), and was adapted to suit the requirements of each database. No date restrictions were applied to the search to ensure that all relevant research was captured.

Articles were then assessed against the following inclusion and exclusion criteria. First, articles were eligible for inclusion if the article: (i) described a microlearning application; (ii) utilised mobile/web technology; (iii) was applied in a higher-education setting; (iv) contained an evaluation of the with human participants; (v) published in peerreviewed outlet; and (vi) the article utilised English language. Articles were ineligible for inclusion if: (i) the article was not an original contribution (e.g. review article); (ii) the article did not report an evaluation with human participants (e.g. articles that described only a system architecture); or (iii) the article's full-text was not available (e.g. conference abstract).

\subsection{Analysis}

The high heterogeneity of the research designs, samples, measures, and educational topics of the studies included in this review meant that a quantitative, meta-analytic synthesis was not possible. Instead, a best evidence narrative review synthesis was conducted by identifying the key themes in research applications and methods. Each article identified for inclusion was reviewed and the key findings relevant to the current study's areas of focus were extracted: article characteristics, methods for microlearning design, educational outcomes, and learning and teaching experience.

\section{Results}

\subsection{Article and Study Characteristics}


The literature search was conducted on $13^{\text {th }}$ January, 2020 and yielded 715 nonduplicate conference and journal articles of potential interest, with 40 of these articles meeting the criteria for inclusion in this review (see Figure 1 and Table 1 for list of articles). The earliest included article was published in 2011, with the latest study published in 2020 .

\section{TABLE 1 GOES HERE}

The included studies applied microlearning to a wide range of academic subjects, predominantly computer science and IT $(n=13)$ and foreign languages courses $(n=11)$. These types of subjects appear to translate well to microlearning materials. Other subject areas included engineering $(n=5)$, art/animation $(n=2)$, medicine $(n=1)$, e-business $(n=1)$, journalism $(n=1)$, teacher education $(n=1)$, urban planning $(n=1)$, and garden architecture $(n=1)$. One study explored the benefits of microlearning across three different areas (digital life, operations management, and supporting people living with dementia), while two studies did not disclose the specific educational focus. Of the included studies, the majority were conducted with students in China $(n=17)$, followed by the USA $(n=4)$, Czech Republic $(n=3)$, Malaysia ( $n=2)$, Canada $(n=2)$, Germany $(n=2)$, and a range of other countries with single studies (UK, Nigeria, South Africa, Japan, Bahrain, Austria, Serbia, Taiwan, Colombia, and Sweden).

\subsection{Article Themes}

Through a process of synthesis and summary, three primary themes emerged: (i) methods for microlearning design and delivery, which includes the variety of microlearning methods and supporting technologies that were reported in the articles; (ii) microlearning for 
improved educational outcomes, which includes studies that focused on objective educational outcomes, such as impacts on academic performance and participation; and, (iii) microlearning for improved learning and teaching experiences, which includes studies that measured the subjective impacts of microlearning into education, on metrics that include motivation to learn, enjoyment, and the user experience of microlearning technologies. The included articles are discussed in terms of these three themes in the following sections.

\subsubsection{Methods for microlearning design}

Across studies, variation in the design of microlearning content and content delivery were identified. The most prominent form of microlearning content explored was short videos less than 15-minutes in length $(\mathrm{n}=23)$, also known as "micro-lectures", which provide students with brief learning opportunities. For example, Wen and Zhang (2015) described the implementation and evaluation of a smartphone-based application for delivering ubiquitous micro-lectures to students so that they can engage with course content at any-time and anyplace. Other types of microlearning content included brief social media posts (Osaigbovo \& Iwegim, 2018), traditional learning materials chunked into smaller modules (e.g. text and multimedia) (Kadhem, 2017; Lili Liu, 2017; Lv et al., 2020), and short, interactive prompts or quizzes to supplement other teaching resources (Dingler et al., 2017; Edge et al., 2012).

The articles reported on a range of different technologies to deliver micro-content to students, including social media platforms (e.g. Instagram, Facebook, and WeChat) (Huang et al., 2019; Osaigbovo \& Iwegim, 2018; Qi, 2017), web-based and e-learning platforms including MOOCs (Aarabi et al., 2016; Bothe et al., 2019; W. Liu, 2018; Lv et al., 2020; Miaomiao \& Lili, 2015; Polasek \& Javorcik, 2019a, 2019b; Subramaniam \& Muniandy, 2019; Wang et al., 2018; Zahirović Suhonjić et al., 2019), smartphone applications (Dingler

et al., 2017; Edge et al., 2011, 2012; Göschlberger, 2017; Kadhem, 2017; L. Liu et al., 2018; Norsanto \& Rosmansyah, 2018; Ohkawa et al., 2019; Ren, 2015; Zhu \& Zhang, 2015), and 
custom-developed platforms utilising web or alternative programming technologies (Correa et al., 2018; Hsu \& Zhou, 2017; Matthews et al., 2014). Mobile and social media delivery platforms were typically chosen due to their popularity amongst student groups. A novel approach utilised by one study involved mobile augmented reality to deliver microlearning content to students (W. Cai \& Chen, 2018), while another study augmented the web browser content accessed by students to provide passive microlearning while completing other tasks (Trusty \& Truong, 2011).

Finally, an emerging sub-theme identified was the use of personalised recommendation systems (identified in $n=6$ studies) to support tailored pathways through microlearning materials (Bothe et al., 2019; Edge et al., 2011, 2012; Erwen \& Wenming, 2017; Hsu \& Zhou, 2017; Wen \& Zhang, 2015). In these studies, the learning system provides recommendations for microlearning content based on either previous learning history, or other contextual factors such as real-world location. For example, Bothe et al. (2019) reported on delivering a personalised curriculum of micro-lectures to students based on their preferences and feedback. Another study used the sensors of a smartphone to notify users to complete vocabulary-based micro-lessons using words related to their current location (Edge et al., 2011).

There were varying outcomes reported in the studies that utilised some form of personalisation or recommendation to students. Bothe et al. (2019) reported that while users were unsure about whether the personalisation of microlearning content had any tangible effect on their learning outcomes, they rated the system positively. Further, Erwen and Wenming (2017) and Wen and Zhang (2015) both reported that students rated positive learning experiences with these personalised microlearning platforms. In terms of increasing performance, Edge et al. (2012) reported that an adaptive mobile flashcard system increased both learner accuracy and confidence. Further, a study that triggered contextual micro-lessons 
based on the user's current location resulted in increased engagement when compared to lessons that were scheduled based on other factors (Edge et al., 2011). There is evidence in the literature that technology-enhanced, personalised learning can provide benefits to students (FitzGerald et al., 2018), offering a promising area for further research.

Overall, these studies show that a range of micro-content and delivery methods have been explored within the broader scope of microlearning. However, it is also clear that there is significant scope to explore the application of microlearning further, including more research on other types of microlearning content beyond micro-lectures which have been the predominant focus of research to date, and investigations into the benefits of emerging educational technologies such as virtual reality, gaming, and personalised, data-driven systems for microlearning.

\subsubsection{Microlearning for improved educational outcomes}

Many studies included in this review explored the impact of technology-based microlearning on objective outcomes of education. These outcomes include a range of metrics, such as measurable changes in academic performance (e.g. grades achieved on invigilated and non-invigilated assessment) and direct measures of participation (e.g. class attendance, frequency of accessing materials via learning management systems, or completion of study modules). It should be noted that many of the studies discussed in this section also assessed subjective outcomes, which are discussed further in Section 3.2.3.

First, there were several studies identified which measured direct improvements in academic scores after students were exposed to course materials delivered as microlearning content. These studies $(n=16)$ evaluated the effectiveness of a microlearning intervention on final exam scores by utilising varying levels of controlled design. In many cases, the studies reported an increase in test scores after students had engaged with microlearning content. In a strong evaluation design, Polasek and Javorcik (2019b) conducted a pilot study with 
microlearning applied to a first-year computer architecture and operating systems course. When compared to a control group, it was found that students in the experimental group achieved significantly better scores on a final exam. Similar results were identified in a range of other studies in this review (Han, 2019; Wen \& Zhang, 2015; Yu, 2016; Zhang, 2017). In contrast, Kävrestad and Nohlberg (2019) found that exam scores for students exposed to micro-lectures were comparable to students who received traditional classroom teaching. Similarly, Trusty and Truong (2011) did not identify a significant difference in scores, though it should be noted that there was no decrease in performance when compared to a group who engaged in more traditional learning. While most studies identified a notable increase in academic performance in students that engaged with microlearning, it is clear that it may not provide the same benefits to all learning situations.

In addition to improvements on final exam score, some studies also explored whether the introduction of microlearning impacted students' participation, such as their frequency and timing of access to learning materials. These analyses were more common in data-driven studies in which the researchers had access to data logs from learning management systems or MOOCs. For example, Ohkawa et al. (2019) tracked the usage patterns of students on a mobile microlearning application that allowed for interrupted learning (e.g. the ability to stop and start the session at any point) compared to a mobile application that only allowed static learning. They found that students who used the interrupted learning application had increased engagement with the learning materials. Correa et al. (2018) report that students engaging in course materials delivered in a microlearning format were quicker to complete tasks and also completed more iterations than students in the non microlearning group. Other research has found that students studying in a microlearning format completed tasks quicker and more accurately than other students (Gao, 2018). Interestingly, the type of learning task and the platform of delivery may also influence the optimal time for engagement with 
learning materials in a microlearning environment. Several studies explored the utilisation of a user's idle time when interacting with other services (e.g. chat) to deliver short learning tasks (defined as "wait-learning"), with tasks that were delivered immediately after the user had completed an interaction (e.g. sending a chat message) being responded to more frequently than tasks delivered after a longer delay (C. J. Cai et al., 2014, 2015; Dingler et al., 2017; Huang et al., 2019; Ren, 2015).

Interestingly, one article explored the completion of smaller learning modules embedded within a larger course as an educational outcome itself, without having students engage in a formal evaluation of knowledge retainment at the end of study. Leach and Hadi (2017) developed a MOOC consisting of a series of 1-2 minute modules that made up a larger course. Participants were awarded badges for completing each module, and a certificate for completing the entire course. The results showed that a significantly larger proportion of students earned badges for completing individual modules than those who completed the entire course. Further, by not restricting access to any modules, the authors witnessed nonlinear educational pathways whereby different students approached the modules in a different order. While no evaluation was conducted to determine whether these students had increased academic performance, the authors recommend that this is an area that should be considered in future research, as such students may be seeking to complement existing knowledge through the use of shorter learning experiences without a desire or need to finish a course in its entirety.

While the results appear positive overall in terms of improving students' educational outcomes and participation, it should be noted that there were some studies that did not notice significant improvements when compared to traditional teaching. For example, Subramaniam and Muniandy (2019) evaluated micro-lectures in the context of flipped-classroom delivery and concluded that while students were highly engaged, there did not appear to be significant 
differences when compared to a didactic teaching model. Similarly, Kävrestad and Nohlberg (2019) implemented micro-lectures in a computer science course and noted that exam scores were comparable to students who engaged in traditional classroom lectures. While these studies may not have seen improvements in students' educational outcomes or participation when introducing microlearning, it is noted that results were comparable to traditional methods, which indicates that microlearning may provide a suitable alternative to traditional teaching and learning approaches.

\subsubsection{Microlearning for improved learning and teaching experiences}

While improvements to students' educational outcomes and participation are important, it is also relevant to consider any impacts that alternative teaching methods have on the overall learning experience. Many studies included in this review explored the benefits of technology-based microlearning for improving student learning experiences, when compared to traditional teaching and learning techniques. Student learning experience covers a range of subjective metrics, including students' perceived competence, motivation to study, and enjoyment. Further, the learning experience also covers usability aspects of the technology that is delivering the microlearning content, such as perceived usefulness, perceived ease-of-use, and broader acceptance of technology.

The introduction of microlearning has been demonstrated to improve the student experience, based on subjective ratings from students. For example, Aarabi et al. (2016) report that by converting longer video content into short, 1-2 minute modules resulted in an $18 \%$ increase in positive feedback on course reviews. In terms of learning motivation, Cai and Chen (2018) report that microlearning content delivered via mobile augmented reality increased both learning performance and self-reported motivation to learn. Evidence also suggests that learning interest and efficiency is also improved through microlearning (Correa et al., 2018; Han, 2019; Yu, 2016). For micro-lectures specifically, students rated that the 
ability to watch more lessons in a single session (due to shorter duration) and ease of repeat viewing as improving the learning experience (Van Der Westhuizen \& Golightly, 2015), with some students preferring the micro-lecture format over traditional classroom lectures (Kävrestad \& Nohlberg, 2019).

Interestingly, a few studies also considered the impact of having students engage in the development of microlearning content which was later presented to their peers as part of the learning process. For example, Zahirović Suhonjić et al. (2019) explored the combination of microlearning and crowdsourcing in a collaborative learning environment whereby students created and shared short video lessons to form micro-courses completed by other students. Experiments identified that students rated an increased motivation to learn and satisfaction when participating in the creation of microlearning materials. Van Der Westhuizzen and Golightly (2015) explored the impact of peer assessment on student created micro-videos, concluding that students benefited from creating and sharing micro-videos with peers due to immediate feedback and the ability to compare their work to peers. While these preliminary studies report promising results, further studies should explore the impact of student-created microlearning content on the teaching and learning experience. This model may also provide benefits to the aforementioned workload issues faced by teaching staff in creating microlearning content, by involving students in the process as part of the learning experience.

It is encouraging that many studies included in the review also explored the user experience of the introduced technologies and microlearning content through qualitative evaluations (Brebera, 2017; Dingler et al., 2017; Erwen \& Wenming, 2017; Han, 2019; Lili Liu, 2017; W. Liu, 2018; Matthews et al., 2014; Ohkawa et al., 2019; Osaigbovo \& Iwegim, 2018; Polasek \& Javorcik, 2019a, 2019b; Van Der Westhuizen \& Golightly, 2015; Wen \& Zhang, 2015; Yu, 2016; Zhu \& Zhang, 2015). This is an important consideration as it is likely 
that the format of content and supporting technologies will also impact on the effectiveness of microlearning and the overall teaching and learning experience of the students. Osaigbovo and Iwegim (2018) explored the perceptions of students on microlearning content delivered via Facebook and Instagram, reporting that students found the interface of Instagram to be more conducive to learning which suggests that the visual design and usability of supporting technology has an impact on the learning experience. Further, Van Der Westhuizen and Golightly (2015) considered the user experience of a micro-lecture platform for learning; while students rated their experience with the videos highly, they provided low ratings for system reliability due to issues with accessing the content when required. Future studies should not only consider the impact of microlearning on improving the student experience, but also consider the impact of technology choices for different microlearning content types and fields of education.

While most of the studies in this review focused on the benefits of microlearning for improving the learning experience of students, fewer studies considered the impact on workload and maintenance for teaching staff looking to implement microlearning in their own classes. First, Liu (2017) concluded that while microlearning in the online space provides many benefits for students, it is still recommended that teachers should be actively involved in the role of content guides. Further, Erwen and Wenming (2017) report that while teachers expressed that the introduction of microlearning afforded more freedom in content design and less time spent on content delivery, there was a significant increase in the time and effort spent prior to the teaching semester on developing suitable micro-lectures for students. Future research should consider efficient and effective microlearning design to maximise student learning experiences within the resources available to teachers.

\section{Discussion}


This review aimed to synthesise the literature on technology-based microlearning in the context of higher education, highlighting current research and applications in the classroom and online. A range of studies were identified exploring the impacts of microlearning for educational outcomes, as well as potential benefits for both the learning and teaching experience. Overall, it was found that microlearning has a positive impact on students' educational outcomes, participation and engagement, and contributes to a positive learning and teaching experience. These findings have important implications for the design and delivery of teaching materials in higher education, particularly in settings that involve the use of technology-based learning and flexible, non-traditional learning and teaching modes.

The first aim of the study was to map the methods and supporting technologies explored in research to deliver and evaluate microlearning in the higher education context. Overall, the included studies represent a range of learning environments, academic subjects and geographical contexts. It was found that research has predominantly explored the benefits of microlearning for learning a second language, followed by several studies on microlearning applied to various areas of computer science or information technology. Limited research had explored microlearning in other educational areas such as engineering, art/animation, medicine, and journalism, requiring further research to examine its suitability across domains and disciplines. In terms of microlearning features, micro-videos and lectures of shorter than 15 minutes in duration have been the most researched content delivery method for teaching. In terms of supporting technologies, there has been more diversity in research with studies exploring microlearning delivered through web-based learning management systems, MOOCs, smartphone applications, custom platforms, and mobile augmented reality. Some studies have also demonstrated the benefits of incorporating personalisation and tailoring methods into these microlearning technologies to personalise the learning experience for students, with positive results. Finally, it is noteworthy that there is a strong 
representation in the research on student cohorts from countries with a high human development index (HDI), which may be indicative of a technology gap. The available evidence from studies conducted in lower HDI countries is promising, which suggests that microlearning may be a good solution for deploying courses in these countries.

Second, this study aimed to explore the impact of technology-supported microlearning on objective educational outcomes in higher education, such as academic performance and student participation. In terms of academic outcomes, many studies evaluated a microlearning platform in comparison with a traditional learning environment by measuring the results of test scores. It was found that in most cases, students engaging in microlearning either saw significant increases in their test scores, with only a small number of studies identifying no improvement beyond traditional classroom teaching methods. Similarly, microlearning was found to increase student participation levels compared to those reported in traditional classroom settings. This implies that microlearning can be an acceptable supplement or even alternative to traditional classroom teaching, though more research is needed to delineate the contexts in which it is most effective. Interestingly, several studies identified that microlearning can provide students with different pathways through learning content and unique opportunities in which to engage in learning during their daily life (e.g. "wait-learning"). Overall, this demonstrates the potential flexibility of microlearning in delivering intuitive learning experiences to students, which may result in increased engagement and learning outcomes.

The third aim of this scoping review was to explore the impacts of technologysupported microlearning on the subjective learning and teaching experience of students in higher education. On the whole, studies that focused on the learning experience identified that microlearning can increase students' motivation to learn, confidence, and satisfaction. Results indicated that students reported particular satisfaction from the ability to engage with 
microlearning content repeatedly, allowing them to focus on the areas in which they feel the need to study in more detail. In contrast, there were relatively fewer studies that considered the impacts of technology-supported microlearning on the teaching experience, in terms of additional effort in creating and managing a microlearning environment. For those studies that did acknowledge impacts on the teaching experience, it appears that there is a trade-off between flexibility and increased workload in generating appropriate microlearning content. Interestingly, a few studies noted that involving students in the creation of microlearning content can also improve students' motivation to learn and satisfaction with learning. While it is not clear whether student-developed microlearning content can replace teacher-developed content, it could potentially complement such material and reduce the workload involved in creating microlearning content, while providing students with an additional learning experience.

Overall, the findings of this scoping review across all three themes of synthesis indicate that microlearning is applicable to a range of content types, supporting technologies, educational subjects, and can provide positive benefits for academic outcomes, student participation, and improve the student experience. These findings have implications for the design and delivery of microlearning content, and should guide educators on possible methods and technologies that they could incorporate into their own higher education classrooms. The strongest evidence pertains specifically to micro-lectures which have been repeatedly demonstrated as effective. The evidence is also positive for other technologies and microlearning formats, indicating that education practitioners should experiment further. It is also likely that these findings will be applicable to other areas outside of higher education, such as workplace training, and primary and secondary education. Preliminary research in these areas have indicated similar impacts on educational outcomes, student engagement, and 
the learning and teaching experience (Erradi et al., 2013; Göschlberger \& Bruck, 2017; Nikou \& Economides, 2018; Norsanto \& Rosmansyah, 2018).

Importantly, the current study has several limitations that should be considered when interpreting the results. First, the outcomes of a review are limited by its search and synthesis methodologies. Due to the scoping nature of this review to map the broad application of technology-supported microlearning to higher education, there was a distinct lack of consistency in the microlearning techniques and evaluation methods used in the research, which made it difficult to conduct a quantitative, meta-analytic synthesis. Future work could attempt to conduct such synthesis, focusing on studies which utilised specific microlearning features or technologies and had similar evaluation methods to delineate the impacts on educational outcomes. In terms of limitations of the research included in this review that may impact on the application of its findings into practice, there was a lack of research focusing specifically on the impact of microlearning on non-traditional students, for example those students facing additional barriers to studying with technology. Further, the majority of research has explored the use of micro-lectures, with fewer studies comparatively exploring alternative methods for delivering microlearning content to students. While it was promising to see a range of technologies utilised to deliver microlearning content (e.g. mobile, web, augmented reality, custom software), future research should also aim to compare the benefits and impact of individual technologies for supporting microlearning, to provide practitioners with a distinct set of design guidelines to use in their own classroom and teaching practice.

While the current literature provides an indication into the potential impacts of technology-supported microlearning in higher education, it is clear that there is significant scope for further research to increase this body of knowledge. A notable limitation is the small-scale, preliminary research designs predominantly used across the different studies included in this review. Many studies reported the results of pilot work to investigate novel 
technologies and applications of microlearning, and investigated with only small sample sizes or minor learning tasks. Further, there were varying levels of rigour in the design of the studies, with few utilising randomised, controlled experimental designs. This may be due to ethical issues in withholding an educational intervention from groups of students who are undertaking real coursework that contributes to a qualification. Such research design limitations should be carefully considered when interpreting the current study's findings. Future work needs to balance the need for rigorous research designs against meeting the needs of students in a fair and ethical way.

\section{Conclusions}

In conclusion, the research into microlearning in higher education has focused on a range of methods, technologies, and educational disciplines. It has been shown to provide benefits for most students in terms of increasing educational outcomes and engagement with learning. Further, overall students report high levels of satisfaction when engaging with microlearning, reporting benefits for motivation to learn and increased confidence. While much of the literature has reported on relatively small-scale evaluations of microlearning systems in a variety of discipline areas, there is a distinct and consistent trend in the aggregated literature demonstrating its effectiveness in higher education. With a continued trend towards flexible, blended and online learning in higher education, future research should continue to explore this method of learning and its implications on student outcomes and learning experiences. 


\section{References}

Aarabi, P., Norouzi, N., Wu, J., \& Spears, M. (2016). 7 surprising lessons learned from teaching iOS programming to 30,000+ MOOC students. 2016 IEEE Frontiers in Education Conference (FIE), 1-4.

Appana, S. (2008). A review of benefits and limitations of online learning in the context of the student, the instructor and the tenured faculty. International Journal on E-Learning, $7(1), 5-22$.

Arksey, H., \& O’Malley, L. (2005). Scoping studies: towards a methodological framework. International Journal of Social Research Methodology, 8(1), 19-32.

Boelens, R., De Wever, B., \& Voet, M. (2017). Four key challenges to the design of blended learning: A systematic literature review. Educational Research Review, 22, 1-18.

Bothe, M., Renz, J., Rohloff, T., \& Meinel, C. (2019). From MOOCs to Micro Learning Activities. 2019 IEEE Global Engineering Education Conference (EDUCON), 280-288.

Bozkurt, A., Akgün-Özbek, E., \& Zawacki-Richter, O. (2017). Trends and patterns in massive open online courses: Review and content analysis of research on MOOCs (2008-2015). International Review of Research in Open and Distributed Learning: IRRODL, 18(5), 118-147.

Brebera, P. (2017). Microlearning in Foreign Language Courses: A Threat or a Promise? European Conference on E-Learning, 85-93.

Cai, C. J., Guo, P. J., Glass, J., \& Miller, R. C. (2014). Wait-learning: leveraging conversational dead time for second language education. CHI '14 Extended Abstracts on Human Factors in Computing Systems, 2239-2244.

Cai, C. J., Guo, P. J., Glass, J. R., \& Miller, R. C. (2015). Wait-Learning: Leveraging Wait Time for Second Language Education. Proceedings of the 33rd Annual ACM Conference on Human Factors in Computing Systems, 3701-3710. 
Cai, W., \& Chen, Q. (2018). An Experimental Research of Augmented Reality Technology from the Perspective of Mobile Learning. 2018 IEEE International Conference on Teaching, Assessment, and Learning for Engineering (TALE), 912-915.

Correa, D., Isaza, F. A., Mazo, R., \& Giraldo, G. L. (2018). CME--A Web Application Framework Learning Technique Based on Concerns, Micro-Learning and Examples. International Conference on Web Engineering, 17-32.

Daniel, B. K. (2019). Big Data and data science: A critical review of issues for educational research: Critical issues for educational research. British Journal of Educational Technology: Journal of the Council for Educational Technology, 50(1), 101-113.

De Gagne, J. C., Park, H. K., Hall, K., Woodward, A., Yamane, S., \& Kim, S. S. (2019). Microlearning in Health Professions Education: Scoping Review. JMIR Medical Education, 5(2), e13997.

Dingler, T., Weber, D., Pielot, M., Cooper, J., Chang, C.-C., \& Henze, N. (2017). Language learning on-the-go: opportune moments and design of mobile microlearning sessions. Proceedings of the 19th International Conference on Human-Computer Interaction with Mobile Devices and Services, 1-12.

Edge, D., Fitchett, S., Whitney, M., \& Landay, J. (2012). MemReflex: adaptive flashcards for mobile microlearning. Proceedings of the 14th International Conference on HumanComputer Interaction with Mobile Devices and Services, 431-440.

Edge, D., Searle, E., Chiu, K., Zhao, J., \& Landay, J. A. (2011). MicroMandarin: mobile language learning in context. Proceedings of the SIGCHI Conference on Human Factors in Computing Systems, 3169-3178.

Erradi, A., Almerekhi, H., \& Nahia, S. (2013). Game-Based Micro-learning Approach for Language Vocabulary Acquisition Using LingoSnacks. 2013 IEEE 13th International Conference on Advanced Learning Technologies, 235-237. 
Erwen, Z., \& Wenming, Z. (2017). Construction and Application of MOOC-based College English Micro Lesson System. International Journal of Emerging Technologies in Learning (iJET), 12(02), 155-165.

FitzGerald, E., Jones, A., Kucirkova, N., \& Scanlon, E. (2018). A literature synthesis of personalised technology-enhanced learning: what works and why. Research in Learning Technology, 26. https://doi.org/10.25304/rlt.v26.2095

Fountain, S. B., \& Doyle, K. E. (2012). Learning by Chunking. In N. M. Seel (Ed.), Encyclopedia of the Sciences of Learning (pp. 1814-1817). Springer US.

Gao, N. (2018). Construction and Implementation of Teaching Mode for Digital Mapping based on Interactive Micro-course Technology. International Journal of Emerging Technologies in Learning (iJET), 13(02), 21-32.

Gikas, J., \& Grant, M. M. (2013). Mobile computing devices in higher education: Student perspectives on learning with cellphones, smartphones \& social media. The Internet and Higher Education, 19, 18-26.

Göschlberger, B. (2017). Social Microlearning Motivates Learners to Pursue Higher-Level Cognitive Objectives. E-Learning, E-Education, and Online Training, 201-208.

Göschlberger, B., \& Bruck, P. A. (2017). Gamification in mobile and workplace integrated microlearning. Proceedings of the 19th International Conference on Information Integration and Web-Based Applications \& Services, 545-552.

Han, J.-L. (2019). Micro-Lecture Teaching for Improving the Learning Effect of Non-English Majors at North China Electric Power University. English Language Teaching, 12(6), 209-216.

Hsu, T., \& Zhou, K. (2017). Recommendation of Instructional Video Clips for HTML Learners Based on the ID3 Algorithm. 2017 6th IIAI International Congress on Advanced Applied Informatics (IIAI-AAI), 629-632. 
Huang, W.-B., Liang, W.-X., \& Lai, G.-L. (2019). Microplatform for Autonomous Experimenting on Journalism and Communication. Advances in Computational Science and Computing, 481-488.

Hug, T. (2010). Mobile learning as' microlearning': Conceptual considerations towards enhancements of didactic thinking. International Journal of Mobile and Blended Learning (IJMBL), 2(4), 47-57.

Javorcik, T., \& Polasek, R. (2018). The Basis for Choosing Microlearning Within the Terms of E-Learning in the Context of Student Preferences. 2018 16th International Conference on Emerging eLearning Technologies and Applications (ICETA), 237-244.

Kadhem, H. (2017). Using mobile-based micro-learning to enhance students; retention of IT concepts and skills. 2017 2nd International Conference on Knowledge Engineering and Applications (ICKEA), 128-132.

Kävrestad, J., \& Nohlberg, M. (2019). Using context based micro training to develop OER for the benefit of all. Proceedings of the 15th International Symposium on Open Collaboration, 1-10.

Kirkwood, A., \& Price, L. (2014). Technology-enhanced learning and teaching in higher education: what is "enhanced"and how do we know? A critical literature review. Learning, Media and Technology, 39(1), 6-36.

Kirschner, P. A. (2002). Cognitive load theory: implications of cognitive load theory on the design of learning. Learning and Instruction, 12(1), 1-10.

Leach, M., \& Hadi, S. M. (2017). Supporting, categorising and visualising diverse learner behaviour on MOOCs with modular design and micro-learning. Journal of Computing in Higher Education, 29(1), 147-159.

Lin, J., Sun, G., Shen, J., Cui, T., Yu, P., Xu, D., \& Li, L. (2019). A Survey of Segmentation, Annotation, and Recommendation Techniques in Micro Learning for Next Generation of 
OER. 2019 IEEE 23rd International Conference on Computer Supported Cooperative Work in Design (CSCWD), 152-157.

Liu, L. (2017). Design and Analysis of Online Micro-course of Garden Architecture Design Based on CPC Model. International Journal of Emerging Technologies in Learning (iJET), 12(07), 44-55.

Liu, L., Liu, K., \& Zhao, J. (2018). Development of a Model for Blended Learning Based on BYOD: A Case Study. 2018 Seventh International Conference of Educational Innovation through Technology (EITT), 16-22.

Liu, W. (2018). Design of a Digital Art Teaching Platform Based on Automatic Recording Technology. International Journal of Emerging Technologies in Learning (iJET), 13(08), 185-197.

Lv, M., Liu, H., Zhou, W., \& Zheng, C. (2020). Efficiency model of micro-course study based on cognitive psychology in the college. Computers in Human Behavior, 107, 106027.

Matthews, R., Hin, H. S., \& Choo, K. A. (2014). Learning Object to Enhance Introductory Programming Understanding: Does the Size Really Matter? Turkish Online Journal of Educational Technology-TOJET, 13(1), 174-183.

Miaomiao, X., \& Lili, W. (2015). Application of Micro Teaching Mode of Network Curriculum in Colleges Basic Courses Based on Cloud Computing Platform. International Journal of Simulation--Systems, Science \& Technology, 16.

Moher, D., Liberati, A., Tetzlaff, J., Altman, D. G., \& PRISMA Group. (2010). Preferred reporting items for systematic reviews and meta-analyses: the PRISMA statement. International Journal of Surgery, 8(5), 336-341.

Nikou, S. A., \& Economides, A. A. (2018). Mobile-Based micro-Learning and Assessment: Impact on learning performance and motivation of high school students. Journal of 
Computer Assisted Tomography, 34(3), 269-278.

Norsanto, D., \& Rosmansyah, Y. (2018). Gamified mobile micro-learning framework: A case study of civil service management learning. 2018 International Conference on Information and Communications Technology (ICOIACT), 146-151.

O'Flaherty, J., \& Phillips, C. (2015). The use of flipped classrooms in higher education: A scoping review. The Internet and Higher Education, 25, 85-95.

Ohkawa, Y., Kodama, M., Konno, Y., Zhao, X., \& Mitsuishi, T. (2019). Development and Evaluation of Smartphone Learning Material for Blended Language Learning. 2019 4th International Conference on Information Technology (InCIT), 108-113.

Osaigbovo, I. I., \& Iwegim, C. F. (2018). Instagram: A niche for microlearning of undergraduate medical microbiology. African Journal of Health Professions Education, 10(2), 75 .

Polasek, R., \& Javorcik, T. (2019a). MicroLearning approach to e-learning course creation and reasons for it. AIP Conference Proceedings, 2186(1), 060015.

Polasek, R., \& Javorcik, T. (2019b). Results of Pilot Study into the Application of MicroLearning in Teaching the Subject Computer Architecture and Operating System Basics. 2019 International Symposium on Educational Technology (ISET), 196-201.

Qi, L. (2017). Application Researches on Engineering Mathematics Teaching and Learning Based on New Communication Technology. 2017 9th International Conference on Measuring Technology and Mechatronics Automation (ICMTMA), 349-352.

Ren, A. (2015). Pull-To-Refresh and Learn: Leveraging Mobile Email Load Time for Education. Proceedings of the 33rd Annual ACM Conference Extended Abstracts on Human Factors in Computing Systems, 145-150.

Semingson, P., Crosslin, M., \& Dellinger, J. (2015). Microlearning as a tool to engage students in online and blended learning. Society for Information Technology \& Teacher 
Education International Conference, 474-479.

Shail, M. S. (2019). Using Micro-learning on Mobile Applications to Increase Knowledge Retention and Work Performance: A Review of Literature. Cureus, 11(8), e5307.

Subhash, S., \& Cudney, E. A. (2018). Gamified learning in higher education: A systematic review of the literature. Computers in Human Behavior, 87, 192-206.

Subramaniam, S. R., \& Muniandy, B. (2019). The effect of flipped classroom on students' engagement. Technology, Knowledge and Learning, 24(3), 355-372.

Trusty, A., \& Truong, K. N. (2011). Augmenting the web for second language vocabulary learning. Proceedings of the SIGCHI Conference on Human Factors in Computing Systems, 3179-3188.

Van Der Westhuizen, C. P., \& Golightly, A. (2015). Video annotation software application for thorough collaborative assessment of and feedback on microteaching lessons in geography education. Journal of Geography in Higher Education, 39(3), 420-436.

Wang, Z., Meehan, K., \& Guo, J. (2018). Teaching with Video Assistance in Embedded Real-Time Operating System. 2018 IEEE Frontiers in Education Conference (FIE), 16.

Wen, C., \& Zhang, J. (2015). Design of a Microlecture Mobile Learning System Based on Smartphone and Web Platforms. IEEE Transactions on Education, 58(3), 203-207.

Yu, K. (2016). Design and Application of Micro-video Course Recording in“ General City Planning” Course. International Journal of Emerging Technologies in Learning, 11(5).

Zahirović Suhonjić, A., Despotović-Zrakić, M., Labus, A., Bogdanović, Z., \& Barać, D. (2019). Fostering students' participation in creating educational content through crowdsourcing. Interactive Learning Environments, 27(1), 72-85.

Zhang, W. (2017). Design a Civil Engineering Micro-lecture Platform based on the ARCS Model Perspective. International Journal of Emerging Technologies in Learning (iJET), 
12(01), 107-118.

Zhu, X., \& Zhang, T. (2015). Development of Mobile Application about Boutique Courses Based on Cross-Platform Software. 2015 International Conference of Educational Innovation through Technology (EITT), 56-58. 


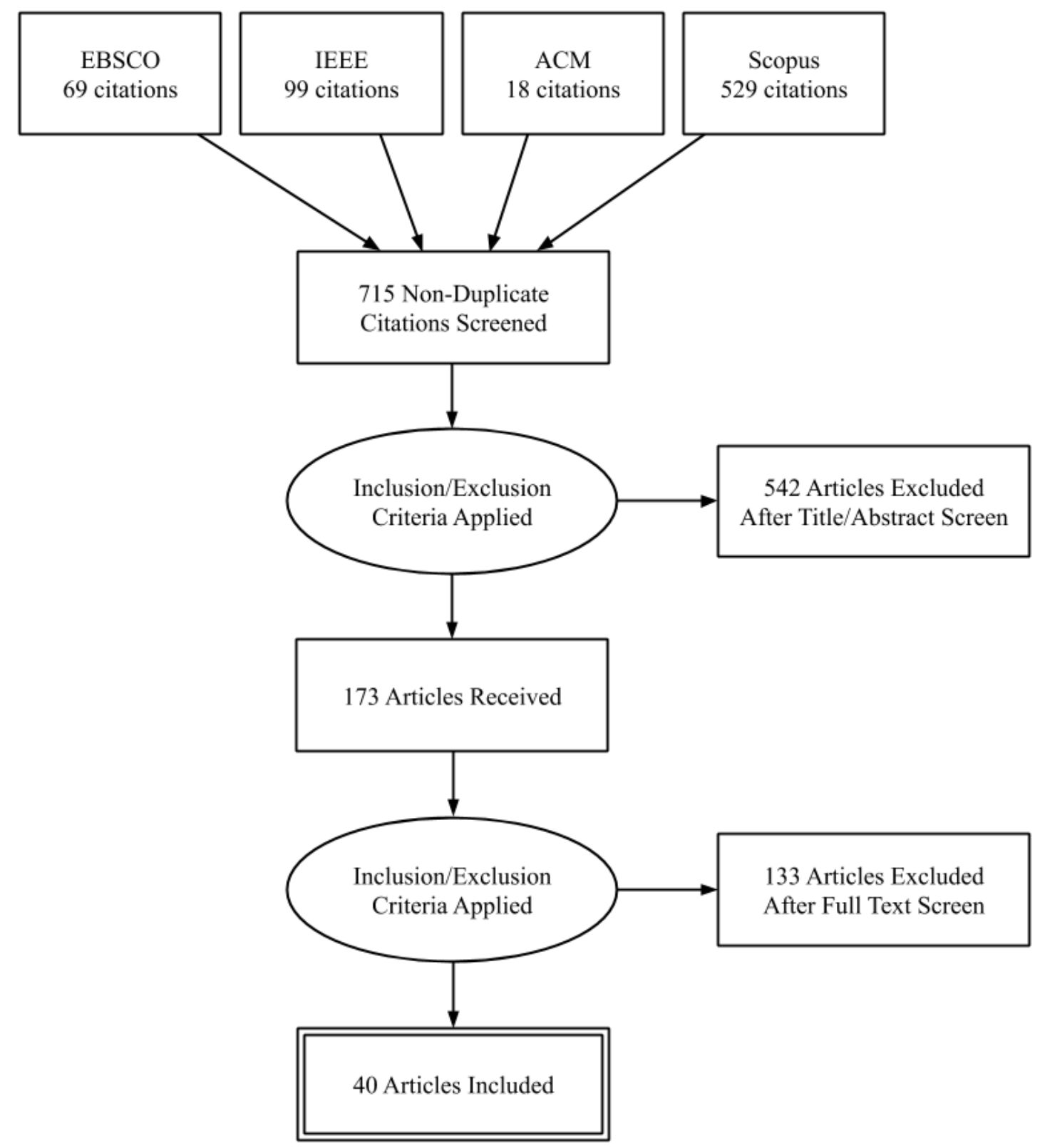

Figure 1. PRISMA procedural flowchart. 
Table 1

Details of articles that met the inclusion criteria

\begin{tabular}{|c|c|c|c|c|c|c|}
\hline Reference & Sample size & Education discipline & Country & Micro-learning features & Technology & Student outcome variable(s) \\
\hline (Aarabi et al., 2016) & 30,162 & Programming & Canada & Micro-lectures, modular content & Web (MOOC) & Student feedback ratings \\
\hline (Bothe et al., 2019) & 535 & Software Engineering & Germany & $\begin{array}{l}\text { Micro-lectures with } \\
\text { recommendations }\end{array}$ & Mobile & Qualitative feedback, usage data \\
\hline (Brebera, 2017) & 1,410 & Foreign Language & $\begin{array}{l}\text { Czech } \\
\text { Republic }\end{array}$ & $\begin{array}{l}\text { Short, interactive lessons and } \\
\text { content }\end{array}$ & $\begin{array}{l}\text { Web and mobile } \\
\text { (Kahoot, Duolingo, } \\
\text { Instagram) }\end{array}$ & Perceived usefulness \\
\hline $\begin{array}{l}\text { (C. J. Cai et al., } \\
\text { 2014) }\end{array}$ & 20 & Foreign Language & USA & $\begin{array}{l}\text { Short exercises displayed } \\
\text { beneath chat window }\end{array}$ & Web (Google Chat) & Vocabulary learned, usage data \\
\hline $\begin{array}{l}\text { (C. J. Cai et al., } \\
\text { 2015) }\end{array}$ & 5 & Foreign Language & USA & $\begin{array}{l}\text { Short exercises displayed } \\
\text { beneath chat window }\end{array}$ & Web (Google Chat) & Usability ratings \\
\hline $\begin{array}{l}\text { (W. Cai \& Chen, } \\
\text { 2018) }\end{array}$ & 25 & Computing & China & $\begin{array}{l}\text { Short, lessons in augmented } \\
\text { reality format }\end{array}$ & $\begin{array}{l}\text { Mobile (Augmented } \\
\text { Reality) }\end{array}$ & $\begin{array}{l}\text { Learning performance, Usability } \\
\text { ratings }\end{array}$ \\
\hline (Correa et al., 2018) & 15 & Software Engineering & Colombia & $\begin{array}{l}\text { Short, contextual tasks and } \\
\text { readings }\end{array}$ & $\begin{array}{l}\text { Web (custom } \\
\text { platform) }\end{array}$ & $\begin{array}{l}\text { Completion times, satisfaction } \\
\text { ratings }\end{array}$ \\
\hline $\begin{array}{l}\text { (Dingler et al., } \\
\text { 2017) }\end{array}$ & 17 & Foreign Language & Germany & $\begin{array}{l}\text { Short learning tasks within } \\
\text { notifications and app }\end{array}$ & Mobile & $\begin{array}{l}\text { Vocabulary learned, usability } \\
\text { ratings }\end{array}$ \\
\hline (Edge et al., 2012) & 38 & Foreign Language & China & $\begin{array}{l}\text { Flashcard-based learning with } \\
\text { adaptive algorithm }\end{array}$ & Mobile & Vocabulary learned and retained \\
\hline (Edge et al., 2011) & 23 & Foreign Language & China & $\begin{array}{l}\text { Flash-cards with context- } \\
\text { awareness based on location }\end{array}$ & Mobile & Usage data, qualitative feedback \\
\hline $\begin{array}{l}\text { (Erwen \& } \\
\text { Wenming, 2017) }\end{array}$ & $\begin{array}{l}\text { Not } \\
\text { disclosed }\end{array}$ & Foreign Language & China & $\begin{array}{l}\text { Micro-lectures with } \\
\text { recommendations }\end{array}$ & Web (MOOC) & Usability ratings \\
\hline$(\mathrm{Gao}, 2018)$ & 114 & Engineering (Urban & China & Micro-videos, short lessons, & Web and mobile & Exam scores, usage time \\
\hline
\end{tabular}




\begin{tabular}{|c|c|c|c|c|c|c|}
\hline & & Construction) & & exercises and assessments & & \\
\hline $\begin{array}{l}\text { (Göschlberger, } \\
\text { 2017) }\end{array}$ & 100 & Not disclosed & Austria & $\begin{array}{l}\text { Short, interactive activities that } \\
\text { students create, consume and } \\
\text { share with each other }\end{array}$ & Web and mobile & Usage data \\
\hline (Han, 2019) & 122 & Foreign Language & China & Micro-lectures & Web & Exam scores, usability ratings \\
\hline $\begin{array}{l}\text { (Hsu \& Zhou, } \\
\text { 2017) }\end{array}$ & 16 & Web Development & Taiwan & $\begin{array}{l}\text { Micro-lectures with } \\
\text { personalised recommendations }\end{array}$ & Web & $\begin{array}{l}\text { Test scores, cognitive load, self- } \\
\text { efficacy }\end{array}$ \\
\hline (Huang et al., 2019) & 56 & Journalism & China & Micro-lectures & Web (social media) & Usage patterns \\
\hline (Kadhem, 2017) & 22 & $\begin{array}{l}\text { Information } \\
\text { Technology }\end{array}$ & Bahrain & $\begin{array}{l}\text { Micro-messages sent } \\
\text { throughout the day }\end{array}$ & Mobile & Quiz scores \\
\hline $\begin{array}{l}\text { (Kävrestad \& } \\
\text { Nohlberg, 2019) }\end{array}$ & 28 & Computer Science & Sweden & Micro-lectures & Web & Exam scores, qualitative feedback \\
\hline (L. Liu et al., 2018) & 36 & 2D Animation & China & Micro-lectures & Mobile & Exam scores, qualitative feedback \\
\hline $\begin{array}{l}\text { (Leach \& Hadi, } \\
\text { 2017) }\end{array}$ & $\sim 10,000$ & Various & UK & Modular content & Web (MOOC) & $\begin{array}{l}\text { Modules completed, badges } \\
\text { earned }\end{array}$ \\
\hline (Lili Liu, 2017) & 300 & Garden Architecture & China & Micro-lectures & Web and mobile & Usability ratings \\
\hline (W. Liu, 2018) & 100 & Digital Art & China & Micro-lectures & Web & Usability ratings \\
\hline (Lv et al., 2020) & 42 & Engineering & China & Short course materials & Web & $\begin{array}{l}\text { Cognitive time, accuracy, } \\
\text { efficiency }\end{array}$ \\
\hline $\begin{array}{l}\text { (Matthews et al., } \\
\text { 2014) }\end{array}$ & 101 & Programming & Malaysia & Short lessons & Web & Quiz scores, usability ratings \\
\hline $\begin{array}{l}\text { (Miaomiao \& Lili, } \\
\text { 2015) }\end{array}$ & 32 & Computer Science & China & Micro-lectures & Web & Test scores \\
\hline $\begin{array}{l}\text { (Ohkawa et al., } \\
\text { 2019) }\end{array}$ & 218 & Foreign Language & Japan & Short learning content & Mobile & Usability ratings, usage data \\
\hline (Osaigbovo \& & Not & Medicine & Nigeria & Social media posts & Mobile & Usability ratings \\
\hline
\end{tabular}




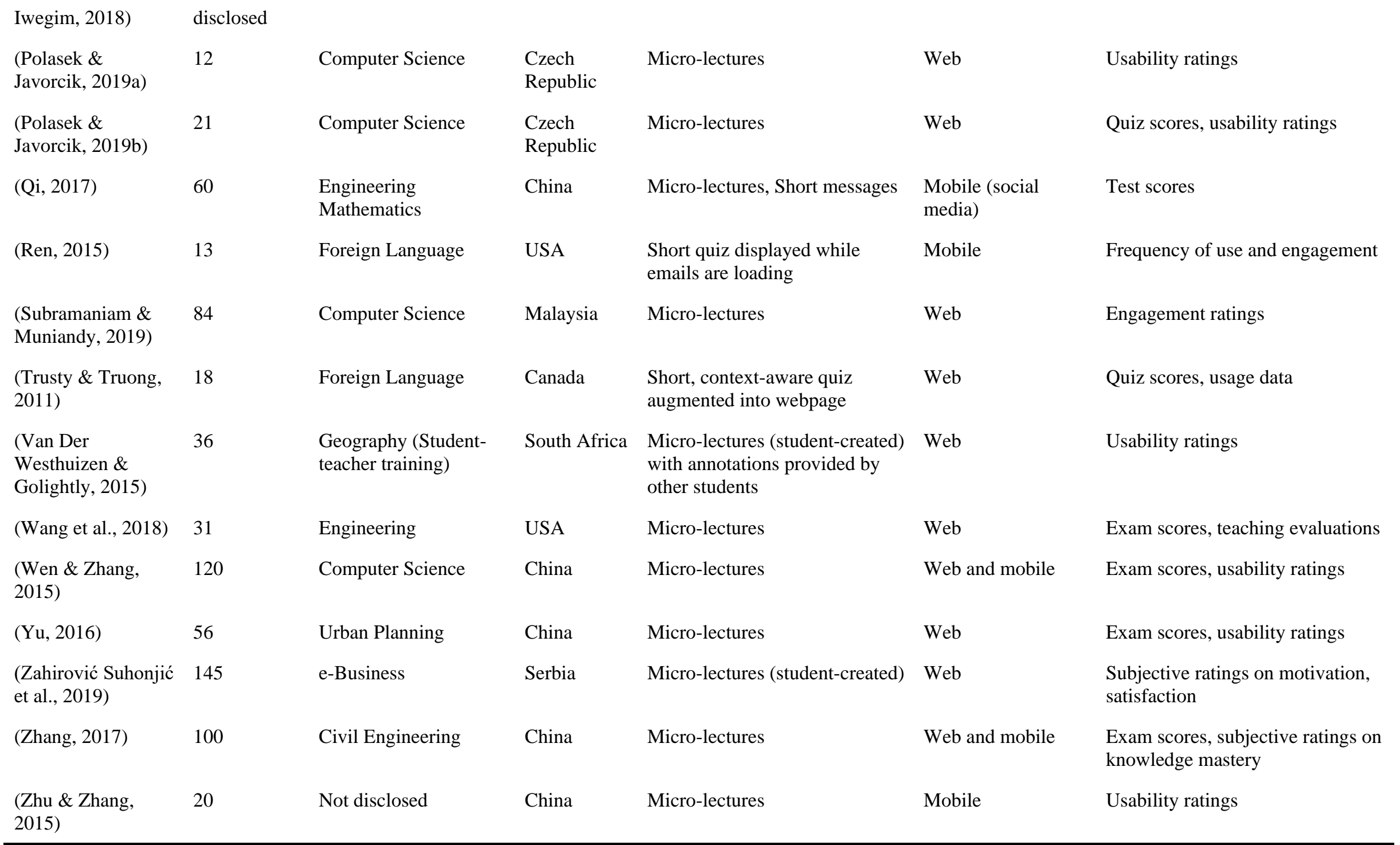




\section{Supplementary Table 1}

Search Strategy

\begin{tabular}{ll}
\hline Construct & Details \\
\hline Mobile/web technologies terms & mobile OR smartphone OR web \\
Education terms & education \\
Micro-learning terms & micro-lesson OR micro lesson OR microlesson OR micro-lecture \\
& $\begin{array}{l}\text { OR micro lecture OR microlecture OR micro-content OR micro } \\
\text { content OR microcontent OR micro-course OR micro course OR } \\
\text { microcourse OR micro-learning OR micro learning OR } \\
\text { microlearning OR wait-learning OR waitlearning OR wait learning }\end{array}$ \\
\hline
\end{tabular}

